\title{
A pilot study of the impact of high-frequency chest wall oscillation in chronic obstructive pulmonary disease patients with mucus hypersecretion
}

\author{
This article was published in the following Dove Press journal: \\ International Journal of COPD \\ 13 November 201 | \\ Number of times this article has been viewed
}

\author{
Indranil Chakravorty' \\ Kamaljit Chahal ${ }^{2}$ \\ Gillian Austin ${ }^{2}$ \\ 'St George's Hospital, London, \\ ${ }^{2}$ East and North Hertfordshire NHS \\ Trust, Lister Hospital and Primary \\ Care Trust, Stevenage, \\ Hertfordshire, UK
}

\begin{abstract}
Introduction: Chronic obstructive pulmonary disease (COPD) patients with mucus hypersecretion tend to demonstrate increased frequency of infective exacerbations and a steeper slope of decline in lung function. Enhanced mucociliary clearance with high-frequency chest wall oscillation (HFCWO) devices previously used in cystic fibrosis and bronchiectasis patients may offer the opportunity for community-based, self-managed therapy to improve quality of life and lung function.
\end{abstract}

Study design and methods: A randomized controlled crossover pilot study of HFCWO compared with conventional treatment was conducted in 22 patients with moderate to severe COPD and mucus hypersecretion. Patients spent 4 weeks using an HFCWO (SmartVest ${ }^{\mathbb{R}}$ ) device and 4 weeks in a conventional phase with a 2 -week washout. Eleven patients started with HFCWO and changed to conventional treatment, whereas the other eleven patients started conventional treatment and crossed over to HFCWO.

Results: The patients were elderly with a mean age of 71 (standard deviation [SD] 10) years and were at the upper end of the normal range of body mass index (25 [SD 4.2] $\left.\mathrm{kg} / \mathrm{m}^{2}\right)$. The majority of patients had moderate to severe COPD with a mean percentage predicted forced expiratory volume in 1 second of 41 (SD 15.6) and percentage predicted forced vital capacity of 73 (SD 17.7). Baseline sputum production was negatively correlated to lung function and positively to St George's Respiratory Questionnaire. Symptom scores and St George's Respiratory Questionnaire symptom dimension improved significantly $(-8, P<0.05)$. Sputum production showed a declining trend in the HFCWO phase, although not reaching statistical significance. The HFCWO device was well tolerated with good reported compliance.

Conclusion: This pilot study demonstrated that patients with advanced COPD and mucus hypersecretion at increased risk of declining lung function tolerated the HFCWO treatment well, leading to improvement in quality of life and reduced symptoms.

Keywords: sputum volume, bronchiectasis, symptom scopes

\section{Background}

Cough, sputum, and shortness of breath are cardinal features of chronic obstructive pulmonary disease (COPD). The natural history of COPD is characterized by a progressive reduction in exercise tolerance and health-related quality of life (HRQoL). ${ }^{1,2}$ The rate of decline in lung function, which is a strong predictor of morbidity and mortality in COPD, ${ }^{3}$ as well as health care utilization, ${ }^{4}$ is higher in patients with mucus hypersecretion and recurrent exacerbations. ${ }^{5-7}$
Correspondence: Indranil Chakravorty University of Hertfordshire, Health Research Building, College Lane, Hatfield, Hertfordshire, UK

Email i.chakravorty@herts.ac.uk 
There is currently a variety of methods to improve mucociliary clearance (MCC) that have been shown to be effective in chronic lung conditions associated with excess mucus production, such as cystic fibrosis (CF) and non-CF bronchiectasis. These include physical therapy techniques such as autogenic drainage, the active cycle of breathing technique, ${ }^{8}$ and adjuvant mechanical devices such as the flutter device ${ }^{9}$ and positive end-expiratory pressure.

High-frequency chest wall oscillation (HFCWO) is a technique utilizing automated pneumatic chest wall percussion delivered through a vest and transmitted to the airways that allows patients to manage their condition independently in their own homes, thus reducing health care costs. HFCWO delivers pressurized air pulses to the external chest wall via the vest, which results in transient cephalad bias airflow spikes in the airways to loosen bronchial mucus so that the patient can more easily expel secretions by coughing. Although HFCWO is well tolerated in children with $\mathrm{CF}^{10-12}$ and has shown demonstrable improvement in $\mathrm{MCC},{ }^{13}$ as well as in some institutionally managed adults with amyotrophic lateral sclerosis, there is currently very little evidence of usage or benefit in adults with COPD. ${ }^{14}$ The in vivo benefit of HFCWO in improving MCC is based on the hypothesis that cyclical mechanical stress on the airway mucosa may improve hydration of the airway surface layer by activation of the P2Y2 receptors. ${ }^{15}$ Intuitively, improved MCC may reduce airflow obstruction, ${ }^{16,17}$ subsequent exacerbations, ${ }^{18,19}$ and rate of lung function decline, leading to improvement in HRQoL. ${ }^{20}$

This pilot study aimed to explore the impact of improved MCC by application of HFCWO on symptoms and HRQoL in patients with advanced COPD and mucus hypersecretion.

\section{Study design and methods}

Ethical approval was obtained from the local research and ethics committee. A randomized crossover study design was used to compare HFCWO with conventional treatment. All COPD patients admitted to hospital or attending the emergency room in the preceding 12 months due to an exacerbation of their disease were invited to participate in the study. These patients were identified from the authors' COPD database. Patients who gave written consent attended for a screening visit. The minimum inclusion criteria were: forced expiratory volume in 1 second $\left(\mathrm{FEV}_{1}\right)<0.8$ predicted, ratio of $\mathrm{FEV}_{1}$ by forced vital capacity $(\mathrm{FVC})\left(\mathrm{FEV}_{1} / \mathrm{FVC}\right)<0.7$, and a daily wet sputum volume of $>25 \mathrm{~mL}$ in the stable state for 3 consecutive days. Exclusion criteria included history of osteoporosis, significant gastro-oesophageal reflux, hiatus hernia, recent acute cardiac event (6 weeks), congestive cardiac failure, any significant musculoskeletal disorders, bronchiectasis, and asthma (excluded by reversibility testing).

Patients were randomized to receive either HFCWO or conventional treatment in phase 1 for 4 weeks, followed by a 2-week "washout" phase. Subjects then crossed over to the alternative phase for the final 4 weeks. Assessments were carried out at the beginning and end of each phase.

The SmartVest ${ }^{\circledR}$ Airway Clearance System (Electromed, Inc, New Prague, MN) was used to deliver the HFCWO treatment for all patients in the HFCWO treatment group. The SmartVest system consists of an inflatable vest, which is worn over the torso, and an air pulse generator that produces and delivers the oscillating air pulses to the vest via a connecting air hose. The HFCWO group received two treatment sessions per day of 20 minutes each (morning and evening). The SmartVest air pulse generator was set at an optimum oscillating frequency of $13-15 \mathrm{~Hz}$, based on individual patient tolerance during the "tuning procedure," and a pressure setting to achieve a tight but comfortably snug fit. Patients in the conventional treatment group followed their own COPD management regimen including all prescription medications, advice on the benefits of regular exercise, and cough clearance of sputum. Medication included a minimum of combination long-acting bronchodilator and inhaled corticosteroid as well as an acting anticholinergic inhaler.

Primary outcome measures included HRQoL, patient tolerability, and compliance of the SmartVest HFCWO device. Secondary outcome measures were spirometry and wet sputum volume. HRQoL was measured with the St George's Respiratory Questionnaire (SGRQ) ${ }^{21}$ as well as with a nonstandardized symptom score measurement, which required subjects to rate five cardinal respiratory symptoms (cough, sputum, wheeze, shortness of breath, and exercise tolerance) as mild $=1$, moderate $=2$, or severe $=3$.

A paired sample $t$-test was used to compare the results between the HFCWO and conventional phase. Baseline correlations were obtained using multiple linear regression analysis. An intention-to-treat analysis model was used for patients who dropped out during each phase of the study. Correction for type 1 errors for multiple statistical tests was not used.

\section{Results}

Thirty subjects (eight female) consented to participate in the pilot study. Twenty-two patients completed the trial. Eight patients developed exacerbations of COPD within the trial period and were consequently withdrawn from the trial. 
The patients were elderly with a mean age of 71 (standard deviation [SD] 10) years and were at the upper end of the normal range of body mass index (25 [SD 4.2] kg/m²).

The majority of patients had moderate to severe COPD with a mean $\mathrm{FEV}_{1} \%$ predicted of 41 (SD 15.6) and percentage predicted forced vital capacity (FVC\%) of 73 (SD 17.7). The baseline daily wet sputum volume was variable with a mean volume of 39 (SD 23) $\mathrm{mL} /$ day, based on a 72-hour collection. Daily sputum expectoration at baseline correlated with a lower $\mathrm{FEV}_{1} \%$ predicted, as shown in Figure 1 (linear regression adjusted $\left.r^{2}=-0.114, P<0.05\right)$.

SGRQ scores at baseline were symptom score 72 (SD 18), activity score 77 (SD17), impact of disease score 51 (SD23), and total score 63 (SD19). Three of the SGRQ dimension scores showed a significant predictive relationship when modeled with $\mathrm{FEV}_{1} \%$ predicted using a linear regression model: symptoms (coefficient $\beta=-0.5, P<0.016$ ), activity $(\beta=-0.7, P=0.007)$, and total score $(\beta=-0.4, P<0.05)$. The SGRQ impact score remained nonsignificant.

There was no significant change in spirometry values (FEV ${ }_{1}$ or FVC) with HFCWO baseline FEV $_{1} 1.05$ (SD 0.37) versus postintervention $\mathrm{FEV}_{1} 1.07$ (SD 0.38) $\mathrm{L}$ or in the conventional phase (baseline $\mathrm{FEV}_{1} 0.97$ [SD 0.37]) versus postintervention $\left(\mathrm{FEV}_{1} 1.01\right.$ [SD 0.36] L, $P=$ not significant), as shown in Figure 2.
Sputum expectoration remained individually variable but showed a trend toward a reduction after HFCWO. In the HFCWO phase, the mean change in sputum volume was $-2.6 \mathrm{~mL}$ (range -53 to $+27 \mathrm{~mL}$ ), and in the conventional phase the mean change was $+6 \mathrm{~mL}$ (range -70 to $+40 \mathrm{~mL}$ ), $P=0.06$.

The baseline sputum volume significantly predicted the change in sputum volume with HFCWO, in a model including age, sex, $\mathrm{FEV}_{1} \%$ predicted, $\mathrm{FVC} \%$, and body mass index (linear regression model coefficient $\beta=0.7, P=0.024$ ), whereas in the conventional phase, none of the variables was found to be significant.

There was a significant improvement in the mean total score in the five-symptom self-reported questionnaire in patients on HFCWO, $P=0.03$. SGRQ scores showed a significant improvement in the symptom dimension $(\partial=-8$, $P=0.028)$, whereas impact of disease, activity, and total scores did not achieve a significant reduction (Table 1). There was no significant change in SGRQ scores in the conventional phase (Figure 3).

\section{Discussion}

Although the effect of HFCWO has been demonstrated to enhance $\mathrm{MCC}$ in children with $\mathrm{CF}^{22}$ as well as in adults with bronchiectasis and neuromuscular disease, ${ }^{23}$ its use

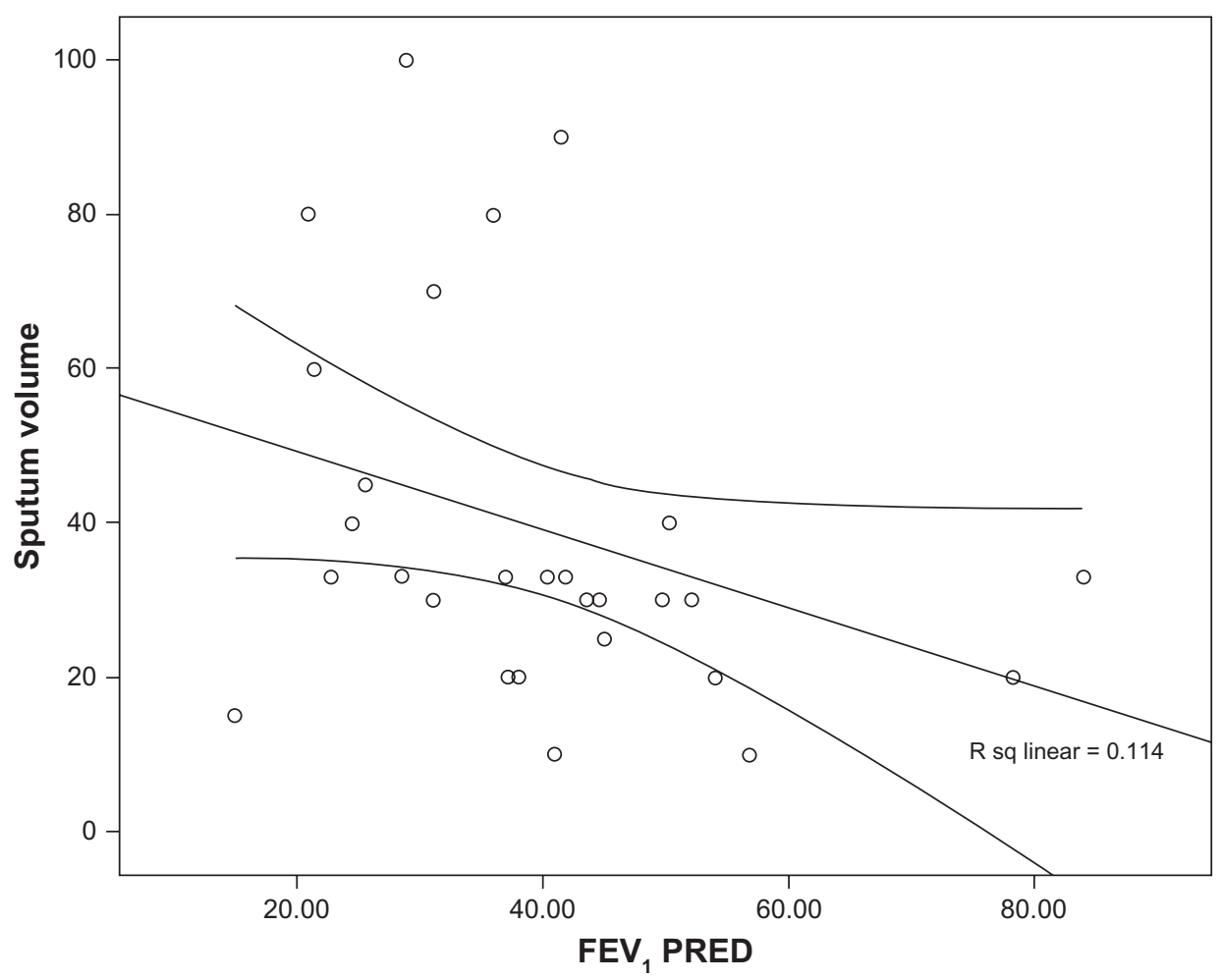

Figure I Scatter plot demonstrating the relationship between sputum volume $(\mathrm{mL})$ and lung function (forced expiratory volume in I second percentage predicted [FEV,PRED]). 


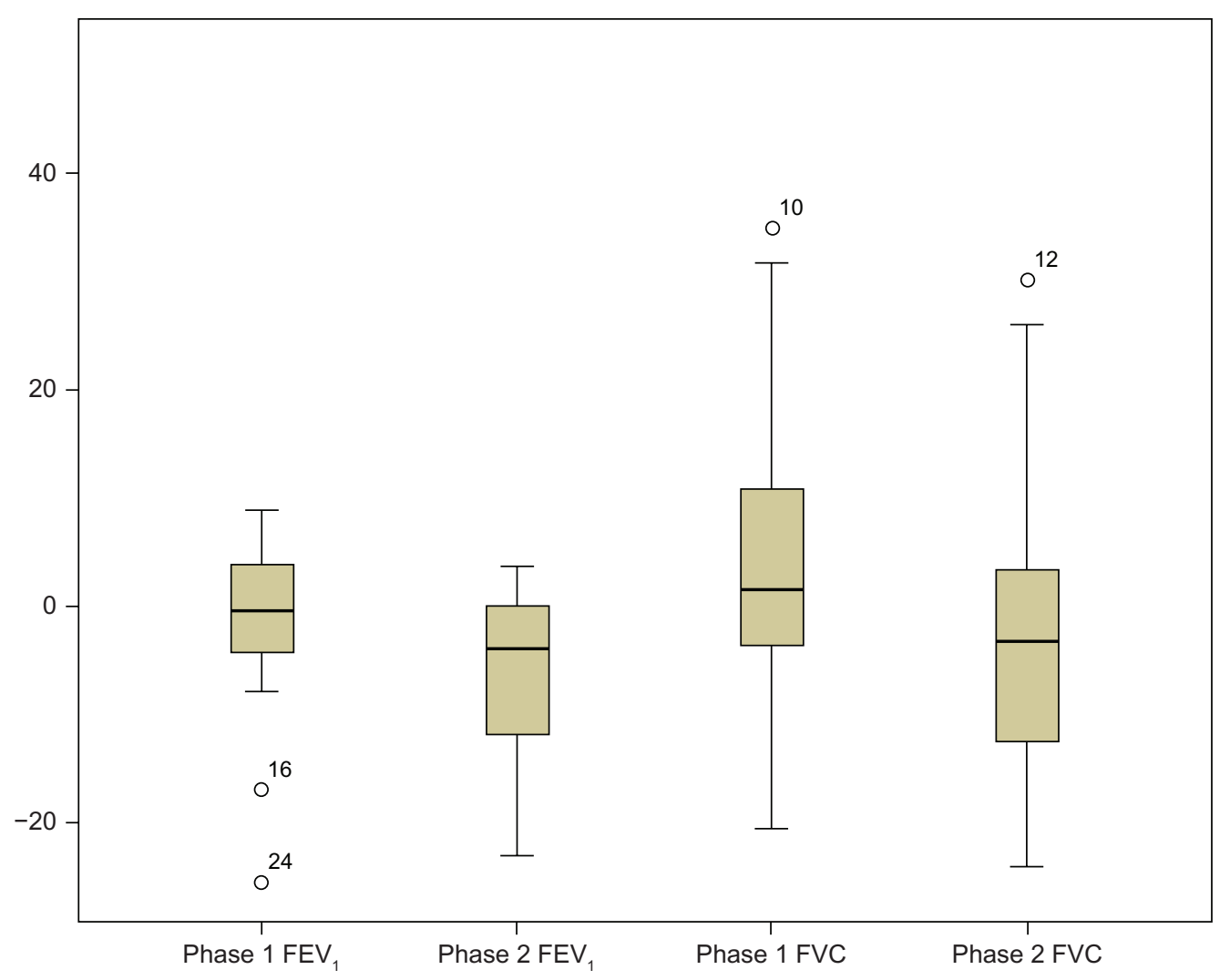

Figure 2 Boxplots representing median and interquartile range change in lung function (predicted forced expiratory volume in I second [FEV $]$ percent predicted and forced vital capacity [FVC] percent predicted) from baseline after intervention in high-frequency chest wall oscillation (phase I) and conventional arm (phase 2 ).

in $\mathrm{COPD}^{24}$ is novel. In this pilot study, the authors set out to explore the suitability of using this modality to improve MCC in patients at the moderate to severe end of the COPD spectrum, where increased sputum production and retention can lead to increased exacerbations, hospital admissions, and a more rapid decline in lung function. ${ }^{25}$ In addition to assessing the impact on HRQoL and sputum, another aim was to assess the tolerability and acceptability of this form of treatment in elderly patients with disabling COPD symptoms and often multiple comorbidities.

Toward this aim, it was found that patients demonstrated a significant improvement in HRQoL dimensions of SGRQ symptom control. The efficient daily clearance of sputum may have led to a decreased daily sputum volume at the end of the HFCWO phase. The HFCWO modality delivered by the SmartVest system was well tolerated in patients who often had significant disability including shortness of breath at rest. No subjects dropped out due to intolerance of the device.

The crossover study design was chosen to reduce the intersubject variability in physiological parameters, as each subject would act as their own matched control. It was decided to have two cohorts of patients, reversing the sequence of $\mathrm{HFCWO/conventional} \mathrm{versus} \mathrm{conventional/HFCWO,} \mathrm{to}$ detect any residual effect on MCC after discontinuing the HFCWO treatment phase during the 2-week washout phase and none was detected. Placebo intervention for this study was deliberately not chosen, as the authors wished to compare HFCWO with "usual treatment," as is currently usual

Table I Symptom and St George's Respiratory Questionnaire (SGRQ)21 dimension scores before and after intervention in each arm of the study

\begin{tabular}{lllllll}
\hline & HFCWO before & HFCWO after & $\boldsymbol{P}$ & Conventional before & Conventional after & $\boldsymbol{P}$ \\
\hline Symptom score & $9.09(3.3)$ & $7.0(4.7)$ & 0.02 & $9.33(2.3)$ & $9.55(2.0)$ & NS \\
SGRQ symptom score & $72(18)$ & $64(16)$ & 0.02 & $70(18)$ & NS \\
SGRQ activity score & $77(17)$ & $78(16)$ & NS & $80(14)$ & $75(19)$ & NS \\
SGRQ impact score & $51(23)$ & $50(19)$ & NS & $49(19)$ & NS \\
SGRQ total score & $63(19)$ & $60(17)$ & NS & $62(15)$ & $62(17)$ & NS \\
\hline
\end{tabular}

Note: Values in brackets indicate the standard deviation.

Abbreviations: FCWO, high-frequency chest wall oscillation; NS, not significant. 


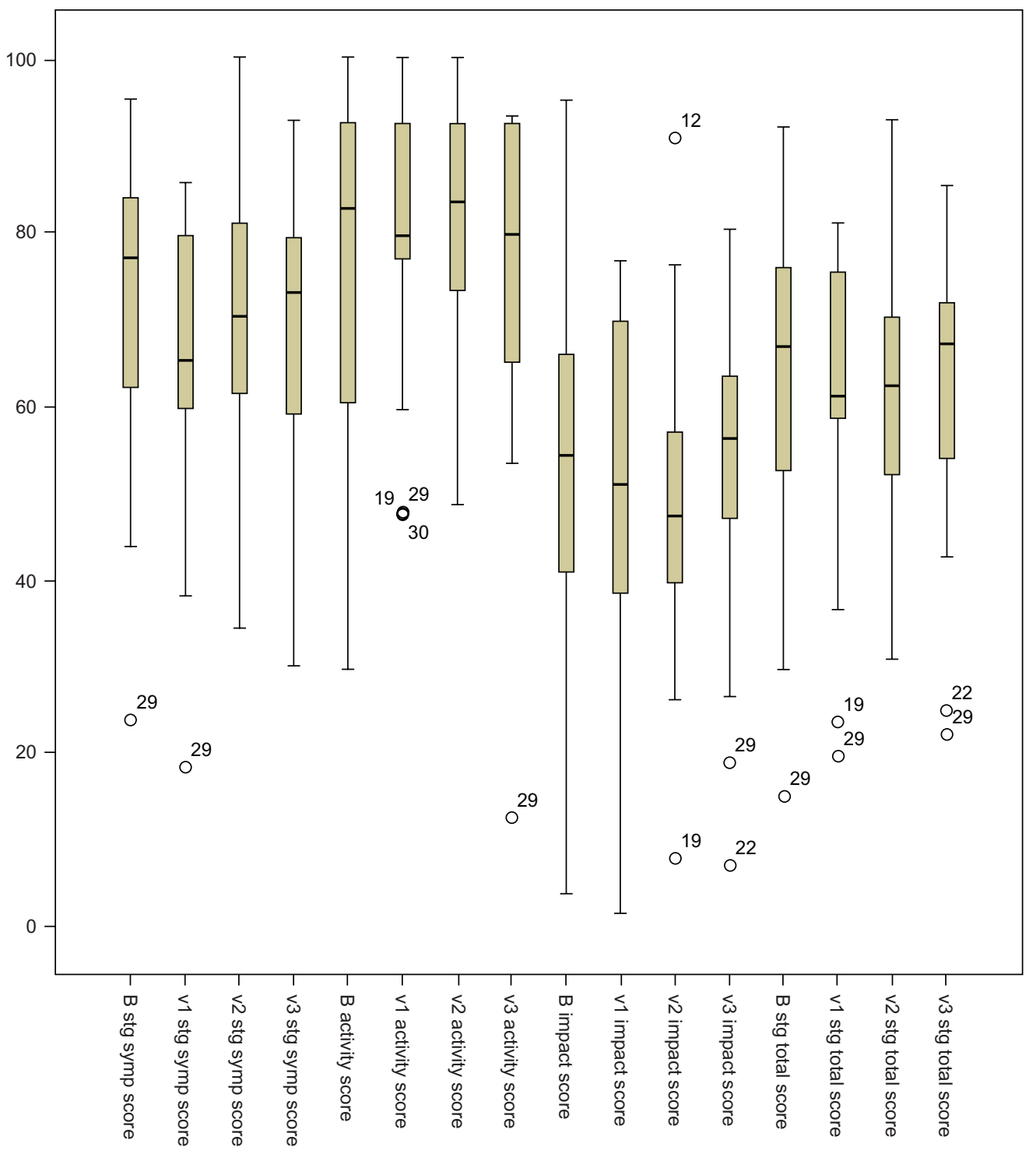

Figure 3 Boxplots demonstrating the St George's Respiratory Questionnaire domain and total scores before and after intervention in both arms of the study (high-frequency chest wall oscillation $\mathrm{B}$ to $\mathrm{vl}$ and conventional phase $\mathrm{v} 2$ to $\mathrm{v} 3$ ).

practice in a real-life setting. It was the authors' hypothesis that patients with severe disabling symptoms from COPD were likely to accept and comply with a treatment that involved setting up and using a vibrating vest around their chest for 20 minutes twice a day only if they experienced a detectable benefit. This has been demonstrated in several trials where compliance levels have been found to be below $50 \%{ }^{26,27}$ However, it is theoretically possible that a proportion of the benefit demonstrated in HRQoL may indeed be due to a placebo "device" effect.

Although this pilot study was not statistically powered, a clinically significant improvement was found in the SGRQ symptom score as well as the SGRQ total score. The SGRQ dimension scores are considered to demonstrate a clinically relevant change if there is a mean reduction in the score of four or more units. ${ }^{28}$ However, when the five-point clinical symptoms score was examined, there was a significant improvement in the HFCWO phase when compared with the conventional phase, which showed no change, although this symptom score was not standardized. When such diseasespecific quality of life (QoL) outcomes are compared with generic QoL measures, the scores were found to demonstrate similar changes. Although in the conventional phase the five-point symptom scores were marginally worse, both of these outcomes improved in the HFCWO arm. Hence, it is likely that the size of improvement detected in the HFCWO phase is due to the intervention, rather than being entirely a placebo effect. 
Analysis revealed a negative correlation between $\mathrm{FEV}_{1}$ and sputum production and a positive correlation between $\mathrm{FEV}_{1}$ and HRQoL. Not only did a low $\mathrm{FEV}_{1}$ relate to a low HRQoL but also to increased sputum production. This would add credence to the current consensus that increased sputum production (and retention) may lead to an increased frequency of exacerbations and, in turn, to an increased rate of decline in $\mathrm{FEV}_{1 .}{ }^{29} \mathrm{As} \mathrm{FEV}_{1}$ decline is still the most reliable parameter of survival, this is a very powerful determinant of outcome in COPD patients.

A $25 \mathrm{~mL} /$ day mucus production threshold was chosen as a criterion for entry into the study after a comprehensive search of the relevant literature. Drawing on previous experience from trials in $\mathrm{CF}$ and non-CF bronchiectatics, the authors were keen to exclude these patients from this trial, intending primarily to focus on the phenotype of $\mathrm{COPD}^{30}$ with airway obstruction and mucus hypersecretion as a novel area of use. The authors' hypothesis of improved MCC leading to a reduction in exacerbation of COPD and rate of decline of $\mathrm{FEV}_{1}$ would be valid only in patients who exhibited both frequent exacerbations and increased mucus production. Patients who had at least one exacerbation in the last 12 months requiring a visit to hospital were invited to take part in this study. The subset of patients who were predominantly suffering from chronic bronchitis rather than having predominantly emphysema, where improved MCC may not be a relevant outcome, were especially sought for inclusion in the study. Clinical experience demonstrated that mucus production in generic COPD patients varied around $10 \pm 10 \mathrm{~mL} /$ day. Hence, the minimum mucus volume was set at a consensus level of $25 \mathrm{~mL} /$ day. High-resolution computed tomography scans were not routinely undertaken in these patients to exclude mild bronchiectasis. It is recognized that a proportion of COPD patients with excess sputum production may have undetected areas of bronchiectasis in their lungs. However, clinical criteria of persistent sputum purulence (in the absence of a clinically detectable exacerbation) and chest radiographic examination were used to avoid patients with obvious bronchiectasis.

Mucus production was widely variable in the study subjects, reflecting the range of $\mathrm{FEV}_{1}$ in this group. There was a consistent trend of reduction in mucus production in the HFCWO phase, when compared with the conventional phase, where the levels of sputum production remained stable or even increased. The baseline mucus production was the primary determinant in predicting the post-treatment mucus production during HFCWO treatment. Overall, there was a trend of reduction in sputum production by the end of the 4-week intervention period. This is likely to be due to efficient daily clearance, as well as a possible reduction in actual sputum production. Patterson et al explored sputum volumes in patients with bronchiectasis and also found significant variability, making this an unreliable measure of effectiveness of MCC modalities. ${ }^{31}$

In a Canadian study, with 15 severe COPD patients given a flutter device to improve MCC, the authors found an improvement in 2-hour postbronchodilator spirometry and exercise tolerance after 1 week of use. ${ }^{9}$ Therefore, it is likely that effective MCC in COPD patients may have an impact on the rate of decline in lung function in the future, although this was not demonstrated significantly in this pilot study.

\section{Conclusion}

This study was designed to explore the feasibility of using the HFCWO modality of mucus clearance in patients with advanced COPD. It was found that that the SmartVest HFCWO device was well tolerated and that subjects demonstrated an improvement in symptom scores and QoL. A significant effect on lung function was not demonstrated, and the wet mucus quantities remained individually variable between patients. It is therefore feasible that HFCWO may have a role in enhancing mucus clearance in COPD patients with the "mucus hypersecretory" phenotype, and future studies may be able to explore the impact of MCC in lung function decline and prevention of exacerbations.

\section{Acknowledgments}

The authors would like to thank Duncan Empey (Bedfordshire and Hertfordshire Postgraduate Medical School, University of Hertfordshire, Hertfordshire, UK), Chet Sievert (Electromed USA), and S Shah (University of Hertfordshire). www. clinicaltrials.gov trial registration NCT00863616.

\section{Disclosure}

The authors report no conflicts of interest in this work.

\section{References}

1. Mapel D, Chen JC, George D, Halbert RJ. The cost of chronic obstructive pulmonary disease and its effects on managed care. Manag Care Interface. 2004;17:61-66.

2. Miller RM, George D, Halbert RJ. Improving the management of chronic obstructive pulmonary disease. J Healthc Qual. 2005;27:42-47.

3. Sin DD, Man SFP. Pharmacotherapy for mortality reduction in chronic obstructive pulmonary disease. Proc Am Thorac Soc. 2006;3:624-629.

4. Niewoehner DE. The impact of severe exacerbations on quality of life and the clinical course of chronic obstructive pulmonary disease. Am J Med. 2006;119(10 suppl 1):38-45.

5. Silverman EK. Exacerbations in chronic obstructive pulmonary disease: do they contribute to disease progression? Proc Am Thorac Soc. 2007;4:586-590. 
6. Langsetmo L, Platt RW, Ernst P, Bourbeau J. Underreporting exacerbation of chronic obstructive pulmonary disease in a longitudinal cohort. Am J Respir Crit Care Med. 2008;177:396-401.

7. Makris D, Moschandreas J, Damianaki A, et al. Exacerbations and lung function decline in COPD: new insights in current and ex-smokers. Respir Med. 2007;101:1305-1312.

8. Pryor JA. Physiotherapy for airway clearance in adults. Eur Respir J. 1999;14:1418-1424.

9. Wolkove N, Baltzan MA Jr, Kamel H, Rotaple M. A randomized trial to evaluate the sustained efficacy of a mucus clearance device in ambulatory patients with chronic obstructive pulmonary disease. Can Respir J. 2004;11:567-572.

10. Livraghi A, Randell SH. Cystic fibrosis and other respiratory diseases of impaired mucus clearance. Toxicol Pathol. 2007;35:116-129.

11. Kendrick AH. Airway clearance techniques in cystic fibrosis. Eur Respir J. 2006;27:1082-1083.

12. Tarran R. Regulation of airway surface liquid volume and mucus transport by active ion transport. Proc Am Thorac Soc. 2004;1:42-46.

13. King M, Phillips DM, Zidulka A, Chang HK. Tracheal mucus clearance in high-frequency oscillation. II: chest wall versus mouth oscillation. Am Rev Respir Dis. 1984;130:703-706.

14. van der Schanns CP. Conventional chest physical therapy for obstructive lung disease. Respir Care. 2007;52:1198-1206.

15. Button B, Boucher RC. Role of mechanical stress in regulating airway surface hydration and mucus clearance rates. Respir Physiol Neurobiol. 2008;163:189-201.

16. Vestbo J, Prescott E, Lange P. Association of chronic mucus hypersecretion with $\mathrm{FEV}_{1}$ decline and chronic obstructive pulmonary disease morbidity. Copenhagen City Heart Study Group. Am J Respir Crit Care Med. 1996;153:1530-1535.

17. Hogg JC. Pathophysiology of airflow limitation in chronic obstructive pulmonary disease. Lancet. 2004;364:709-721.

18. Rodriguez-Roisin R. The airway pathophysiology of COPD: implications for treatment. COPD. 2005;2:253-262.

19. Kobylianskii VI, Gamal EA. Mucoactive therapy and new aspects of the pathogenesis of chronic obstructive pulmonary disease. Klin Med (Mosk). 2006;84:15-24.
20. Bhowmik A, Chahal K, Austin G, Chakravorty I. Improving mucociliary clearance in chronic obstructive pulmonary disease. Respir Med. 2009;103:496-502.

21. Jones PW, Quirk FH, Baveystock CM. The St George's Respiratory Questionnaire. Respir Med. 1991;85 Suppl B:25-31; discussion 33-37.

22. Kempainen RR, Williams CB, Hazelwood AR, et al. Comparison of high-frequency chest wall oscillation with differing waveforms for airway clearance in cystic fibrosis. Chest. 2007;132:1227-1232.

23. Lange DJ, Lechtzin N, Davey C, et al, High-frequency chest wall oscillation in ALS: an exploratory randomized, controlled trial. Neurology. 2006;67:991-997.

24. Piquet J, Brochard L, Isabey D, et al. High frequency chest wall oscillation in patients with chronic air-flow obstruction. Am Rev Respir Dis. 1987;136:1355-1359.

25. Wedzicha JA, Donaldson GC. Exacerbations of chronic obstructive pulmonary disease. Respir Care. 2003;48:1204-1213.

26. Their SL, Yu-Isenberg KS, Leas BF, et al. In chronic disease, nationwide data show poor adherence by patients to medication and by physicians to guidelines. Manag Care. 2008;17:48-52.

27. Gillisen A. Patients' adherence in asthma. J Physiol Pharmacol. 2007; 58(Suppl 5):205-222.

28. Jones PW. St George's Respiratory Questionnaire: MCID. COPD. 2005; 2:75-79.

29. Martinez-Garcia MA, Soler-Cataluna JJ, Perpina-Tordera M, et al. Factors associated with lung function decline in adult patients with stable non-cystic fibrosis bronchiectasis. Chest. 2007;132:1565-1572.

30. Pistolesi M, Camiciottoli G, Paoletti M, et al. Identification of a predominant COPD phenotype in clinical practice. Respir Med. 2008;102:367-376.

31. Patterson JE, Hewitt O, Kent L, et al. Acapella versus 'usual airway clearance' during acute exacerbation in bronchiectasis: a randomized crossover trial. Chron Respir Dis. 2007;4:67-74.
International Journal of COPD

\section{Publish your work in this journal}

The International Journal of COPD is an international, peer-reviewed journal of therapeutics and pharmacology focusing on concise rapid reporting of clinical studies and reviews in COPD. Special focus is given to the pathophysiological processes underlying the disease, intervention programs, patient focused education, and self management protocols.

\section{Dovepress}

This journal is indexed on PubMed Central, MedLine and CAS. The manuscript management system is completely online and includes a very quick and fair peer-review system, which is all easy to use. Visit http://www.dovepress.com/testimonials.php to read real quotes from published authors. 